\title{
Prediction of Demand for Supply Chain using Time Series Predictive Models
}

\author{
Aturika Bhatnagar \\ Research Scholar, \\ Industrial and Production \\ Engineering, Shri G.S. Institute of \\ Technology and Science, Indore, \\ India
}

\author{
Rajeev Gupta \\ Adjunct Faculty, DOMS, Shri G. S. \\ Institute of Technology and \\ Science, Indore, India
}

\author{
G.D. Thakar, PhD \\ Professor, \\ Shri G. S. Institute of Technology \\ and Science, Indore, India
}

\begin{abstract}
Accuracy in the prediction of demand is an important task in any field of business. Prediction of the expected sales ensures the smooth working of an organization as well as helps in maintaining the balance all around the company. For a pump manufacturing company predicting demand can be a tedious task due to the involvement of the multiple factor environmental conditions. In this context, this paper focuses on the prediction of the demand using Holt Winter's model and ARIMA model and then validating their accuracy by MAPE and Theil's-U.
\end{abstract}

\section{General Terms}

ARIMA model, Holt Winter's model, Time Series, Prediction of Demand

\section{Keywords}

Comparison of Holt Winter's model and ARIMA model, UThiel, MAPE, Prediction of sales

\section{INTRODUCTION}

Forecasting plays the most important role and is most frequently used pertinent of predictive analytics since it has a significant impact on the hierarchy of an organisation [14]. Forecasting is futuristic in nature and soft computing is far ahead of traditional forecasting techniques [12].

Though predictions are never accurate but they are the essential starting point of decision making for any organisation. With large data availability and enhanced computational abilities, tools have been developed to provide accuracy to predictions. [28]. Input variables are prerequisites for an effective forecast, together with time-horizon of data available. There are specific tools based on data availability and data patterns [12].

The use of advance technology can help in the increase of production of goods, ensures the timely delivery of the goods as ordered by the customers [29].

Determining the expected values well ahead in time helps in fulfilling the customer orders. It helps to complete the customer's order in time as well as is a business tool which helps in making conclusions ahead of time [29].

Lima S. et al. compared additive and multiplicative WinterHolt method with all three components available, viz. Level, trend and seasonality. They concluded that both models have capabilities of enhancing the accuracy of forecasting. It can be applied to multiple branches of human knowledge from finance to environmental forecasting [24].

Linear and Non- linear methods of quantitative demand forecasting consist of almost 70 different models. Although all the 70 models has, much the less same basic concept, they follow different principals from different area [1].

Amid all the methods available to analyse the data and to predict the future values, ARIMA and Holt methods are extensively used [6-7].

The validity of both forecasting models used is judged by the comparison of its forecast error of the two models. The smaller the error, the better the forecast value produced by the model. The evaluation parameters used to check the efficiency of the ARIMA model and Holt Winter's Method in this paper are, Mean Absolute Percentage Error (MAPE) and U Theil's.

The paper is organised as, section 2 gives the objectives of the study, section 3 gives the details of the methods used as well as the evaluation parameters used for the comparison, section 4 describes the methodology used to carry out this study, section 5 is the results and discussion, section 6 concludes the paper and lists down the limitations and future work.

\section{OBJECTIVES}

The paper walks through the procedure of forecasting the sales demand of the future, using the time series forecasting methods, that is, Holt Winter's and ARIMA model.

Further, we have done a comparative study to figure out the best model for the future prediction of the demands by measuring the mean average percentage error and Theil's U.

It will provide the management with a much accurate demand forecast. It will reduce the inventory burden. It will reduce the chances of shortages by determining to reorder point.

\section{LITERATURE REVIEW}

In previous times, administrators and managers used to depend on their instinct to take the decisions. To decrease their over-dependence on chance and instead become more scientific in dealing with issues, most of the managers shifted to the modern forecasting techniques, which made the results more accurate [17].

Prediction of the buyer behaviour is done by an organisation, to make a strategy which helps in making decisions which enable to schedule a procurement cycle as well as the suitable timing to prevent the inventory holding cost. Most of the time series forecasting methods incorporate statistics as the basis of their models. Any branch that comes under the heading of business can apply these methods. 
Holt-Winter's method is a forecasting method which has its root in exponential smoothing which construct the results based on the previous data. Holt Winter's method also adds some parameters which help with the uncertainty caused by the seasonal changes in the data. The Holt Winters model works in between of the two common methods, i.e., multiplicative model and additive model [11].

ARIMA modelling consists of four steps:

(1) Model-identification is the first step in implementing the ARIMA model. In this step, variables are identified as to analyse them and to figure out the stationary elements of the time series.

(2) The model estimation phase is the second step, all the models which were identified in step one are evaluated and the most decisive one is identified.

(3) The third step, that is, the model validation phase, checks the accuracy of the model identified in the previous step.

(4) The last and the final step, the model forecasting phase, uses the selected model and determines future values of the time series and the results are presented with a confidence interval [11].

Prediction errors are nothing uncommon and most of the results have some or another the error in the results. This errors can be pointed out by using the evaluation parameters. For this paper, we have used the Mean Absolute Percentage Error [28] and U- Thiel.

It has been consistently accepted that MAPE is very adaptive and intuitive with the proper availability of data. It is preferred over other measurements of errors like MSE (Mean Square Error) or MAE (Mean Absolute Error) as it follows the principle of ERM (Empirical Risk Measurement). [2].

MAPE has limitations of outliers (extreme values) if denominator (actual value) is minimal. It has been suggested to use MAAPE instead of MAPE in such circumstances, but as our actual values are consistent enough, so MAPE is applied [23].

Exponential smoothing techniques are commonly used with historical data availability with fluctuations. Holt-Winter's method is also a type of Exponential smoothing forecasting technique with the added advantage of handling seasonality. As our data is seasonal in nature as per graphical pattern observation, we find it suitable to use multiplicative HoltWinter model, although another form of the additive model is also present [12].

Quantitative forecasting applies various predictive models, but there are always chances of errors. The errors should also be predicted with the forecasting. There are various least square techniques like MAD (Mean Absolute Deviation), MAPE, Theil's Coefficient. [28] We have selected MAPE and Theil's coefficient due to benefits as suggested by various researchers.

Theil's coefficient of inequality is one of the statistical forecasting evaluators [4].

\section{THEORETICAL FRAMEWORK}

The study in this paper includes the work and research done in the two models of demand forecasting: ARIMA model and Holt-Winters model to evaluate the accuracy of the two models, we have incorporated the literature of MAPE and UThiel.
Holt-Winters model and ARIMA model are highly favourable proposition to deal with the problems. Holt Winter's describes the trend and seasonality of the data and on the other hand, the ARIMA model specifies the autocorrelations of the data.

\subsection{Holt Winter's Model}

Earlier existing Holt model for forecasting was later upgraded to Holt-Winter model of forecasting adding seasonality aspect with pre-existing trend and level [24].

The HW method practises a nonparametric trend. It applies the mixture of all the 3 exponential smoothing formulas, updating the trend and the seasonal in the data [18].

There are two variations to this method that differ in the nature of the seasonal component.

\subsubsection{Additive Seasonals}

The additive Holt-Winters model is built on a TREND + SEASONAL approach.

$$
\begin{gathered}
L_{t}=\alpha\left(Y_{t}-S_{t-s}\right)+(1-\alpha)\left(L_{t}+B_{t-1}\right) \\
B_{t}=\beta\left(L_{t}-L_{t-1}\right)+(1-\beta) B_{t-1} \\
S_{t}=\gamma\left(Y_{t}-L_{t}\right)+(1-\gamma) S_{t-s} \\
F_{t+m}=L_{t}+m B_{t}+S_{t-s+m} \quad[18]
\end{gathered}
$$

\subsubsection{Multiplicative Seasonals}

The multiplicative Holt-Winters model is built on a TREND $\times$ SEASONAL approach [19].

$$
\begin{gathered}
L_{t}=\alpha\left(Y_{t} \div S_{t-s}\right)+(1-\alpha)\left(L_{t}+B_{t-1}\right) \\
B_{t}=\beta\left(L_{t}-L_{t-1}\right)+(1-\beta) B_{t-1} \\
S_{t}=\gamma\left(Y_{t} \div L_{t}\right)+(1-\gamma) S_{t-s} \\
F_{t+m}=\left(L_{t}+m B_{t}\right) S_{t-s+m} \quad[18]
\end{gathered}
$$

The Holt-Winters method comprises of a forecast equation and three smoothing equations:

i. one equation for the level $\ell_{\mathrm{t}}$,

ii. one equation for the trend $b_{t}$, and

iii. one equation for the seasonal component $\mathrm{s}_{\mathrm{t}}$,

With smoothing parameters $\alpha, \beta^{*}$ and $\gamma$ respectively [20].

The fundamental motivation to utilize the triple exponential smoothing is to apply exponential smoothing to the seasonal parts in addition to the level and the trend. The smoothing is applied across seasons, for example, the seasonal part of the fourth point into the season would be exponentially smoothed with the one from the fourth point of last season, the fourth point two seasons back, and so on [15].

\subsection{ARIMA Model}

The ARIMA model changes the non-fixed time series into fixed time series [30].

This method is useful in many types of condition which involve the constructing of models for discrete time-series [20].

The parameters $p, d$, and $q$ are the autoregressive terms. The ARIMA model is best suitable for the data with high and stable correlation and achieves greater accuracy for simple and short-term prediction [30].

Box and Jenkins in the year 1970, came up with the idea of ARIMA model and hence ARIMA model is also known Box 
and Jenkins method.

An ARIMA model can be understood by outlining each of its components as follows:

- Autoregression $(A R)$ : It uses data from previous time steps as input to a regression equation to predict the value at the next step.

- Integrated $(I)$ : denote to the differencing of initial data to take into consideration the time series to get it stationary, i.e., data are supplanted by the difference between the data and the past values.

- Moving average (MA): fuses the reliance in between an observation and a remaining error from a moving average model applied to lag observations [10].

The parameters of the ARIMA model are defined as follows:

- $\quad p$ : It is called as lag order, it shows the number of lag observations in the model.

- $\quad d$ : It is called the degree of differencing and it shows the number of times that the raw observations are differenced.

- $\quad q$ : It is called the order of moving average and it is the size of the moving average window [8].

In ARIMA model, the future estimation of a variable is a linear combination of previous values and past errors.

\subsection{Evaluation Metrics}

MAPE is the average of the absolute percentage error (APE). The MAPE is one of the most utilized assessment criteria to decide the exactness of the forecast results since it is not scale-dependent and is simple to decipher [23].

In some conditions, unit free methods are needed to be employed and MAPE is best fitted for this kind of circumstances [8].

$$
\begin{aligned}
A P E_{x}= & \left(F_{x}-O_{x}\right) \div O_{x} \\
& \text { And } \\
M A P E= & \left(\Sigma A P E_{x} / N\right) * 100
\end{aligned}
$$

Here, $x$ is the population subgroup; APE is the absolute per cent error; $F$ is the forecast under evaluation; $O$ is the standard of comparison, most often the census; and $N$ is the number of observations [13].

MAPE has several advantages. It is eminent, acknowledged, and provides easy judging of the extent of the error. MAPE, however, also has disadvantages, it is highly influenced by a few outlying errors. Its minimum value is zero, it has no upper bound, and it produces indistinct values when the actual values are zero or near zero, which is a typical event in certain fields [13-15]

Theil's $\mathrm{U}$ measurement is a relative precision measure that contrasts the predicted outcomes and the results of forecasting with minimal past data. It likewise squares the deviations to give more significance to errors and to amplify errors, which can help take out techniques with huge mistakes [19].

Table 1. Interpreting Theil's U [19]

\begin{tabular}{|c|c|}
\hline Theil's U Statistic & Interpretation \\
\hline Less than 1 & Results are better than guessing. \\
\hline 1 & Best prediction \\
\hline More than 1 & Worse prediction \\
\hline
\end{tabular}

Theil's $U$ statistic is calculated by:

$$
\mathrm{U}=\frac{\sum_{t=1}^{n-1}\left(\frac{\widehat{Y} t+1-Y t+1}{Y_{t}}\right)^{\wedge} 2}{\sum_{t=1}^{n-1}\left(\frac{Y_{t+1}-Y_{t}}{Y_{t}}\right)^{\wedge} 2}
$$

Here $Y_{\mathrm{t}}$ is the actual value of a point for a given period $t, n$ is the number of data points, and $\widehat{Y_{t}}$ is the forecasted value [19].

\section{METHODOLOGICAL PROCEDURE}

$\mathrm{We}$, in this paper, have aimed to find a method to forecast the expected sales of a pump manufacturing company. The steps involved in the completion of this research are:

\subsection{Methodological Approach}

The research problem is to predict the future demand for the supply chain so as to reduce the shortage of components for assembly.

The data used for the research was gathered from a manufacturing plant and consists of sales details of the tenure of 4 years, of the most sold models of their pumps.

\subsection{Data Collection}

We have used historical demand data from a pump manufacturing company of the period 2016 to 2019. The data collected was quantitative as required by the nature of the study and justified the procedure used for the analysis.

\subsection{Method of Analysis}

To predict the expected values for the next 2 years, that is, 2020 and 2021, we have used Holt Winter's model and ARIMA Model.

\subsection{Evaluation of Results}

To identify the suitable model for the forecast among the Holt Winter's and ARIMA model, we have done a comparative study for both the methods, using evaluation parameters.

Through the vigorous literature review, we came to the conclusion that MAPE and U- Thiel are the most widely used evaluation parameters to calculate the forecast errors. Determination of the forecast error, aided in defining the bestsuited forecasting method to do the predictions.

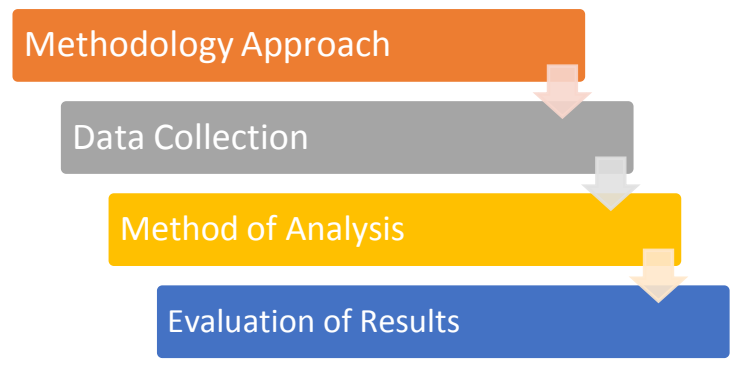

Fig 1: Methodology Procedure

For the comparative analysis of the methodologies to 
determine the best forecasting method, quantitative forecasting techniques are used: Holt Winter's model and ARIMA model. To do a comparison between the two models, we have used MAPE and U-Thiel inequality index (U-Thiel) as performance metrics.

\section{ANALYSIS AND RESULTS}

For the application of Holt Winter's Model and ARIMA model, we have used IBM SPSS. The parameters for the ARIMA model was set at $(0,1$, and 0$)$.

Table 2. Model Description of ARIMA

\begin{tabular}{|c|c|c|c|}
\hline & & Model T & \\
\hline \multirow{2}{*}{$\begin{array}{c}\text { Model } \\
\text { ID }\end{array}$} & $\begin{array}{l}\text { Single } \\
\text { Phase } \\
\text { Pump }\end{array}$ & Model_1 & $\operatorname{ARIMA}(0,0,0)(1,1,0)$ \\
\hline & $\begin{array}{l}\text { KOS } \\
\text { Pump }\end{array}$ & Model_2 & $\operatorname{ARIMA}(0,0,0)(0,1,0)$ \\
\hline & $\begin{array}{l}\text { Three } \\
\text { Phase } \\
\text { Pump }\end{array}$ & Model_3 & $\operatorname{ARIMA}(0,0,0)(0,1,0)$ \\
\hline & $\begin{array}{l}\text { SP } \\
\text { Valve } \\
\text { Pump }\end{array}$ & Model_4 & $\operatorname{ARIMA}(0,0,0)(0,1,0)$ \\
\hline
\end{tabular}

Table 3. Model Description of Holt Winter's Model

\begin{tabular}{|c|c|c|c|}
\hline & Model Type \\
\hline \multirow{3}{*}{$\begin{array}{l}\text { Model } \\
\text { ID }\end{array}$} & $\begin{array}{l}\text { Single } \\
\text { Phase Pump }\end{array}$ & Model_1 & Winters' Additive \\
\hline & KOS Pump & Model_2 & Winters' Additive \\
\hline & $\begin{array}{l}\text { Three Phase } \\
\text { Pump }\end{array}$ & Model_3 & Winters' Additive \\
\hline & $\begin{array}{l}\text { SP Valve } \\
\text { Pump }\end{array}$ & Model_4 & Winters' Additive \\
\hline
\end{tabular}

Figure 2 shows the forecast result of the single-phase pump for the year 2020 and 2021 of the ARIMA model, along with the actual sales data.

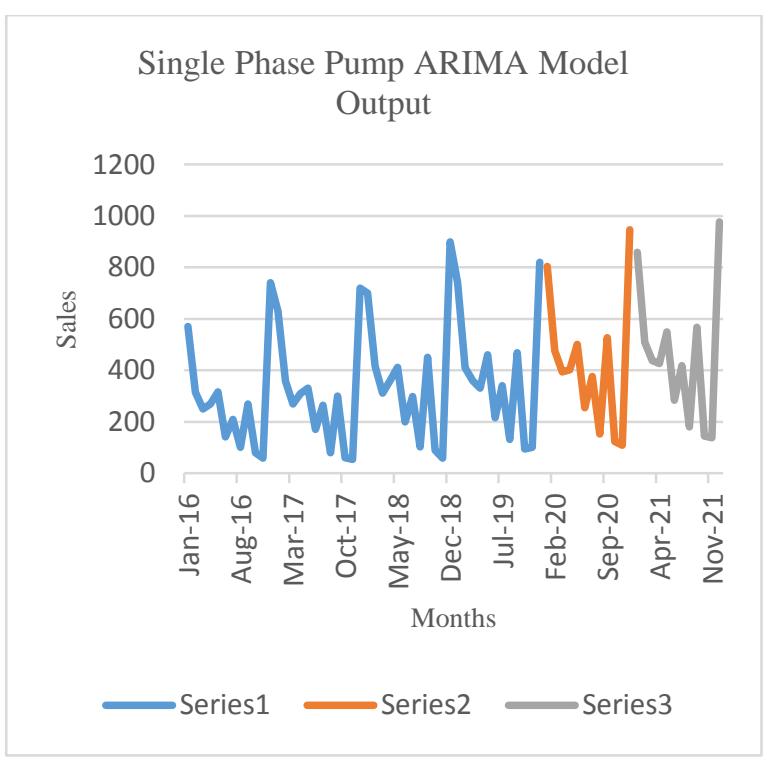

Fig 2: Output of the ARIMA Model Single Phase Pump

Figure 3 demonstrates the forecast result of single-phase pump for the year 2020 and 2021 of the Holt Winter's model, along with the actual sales data.

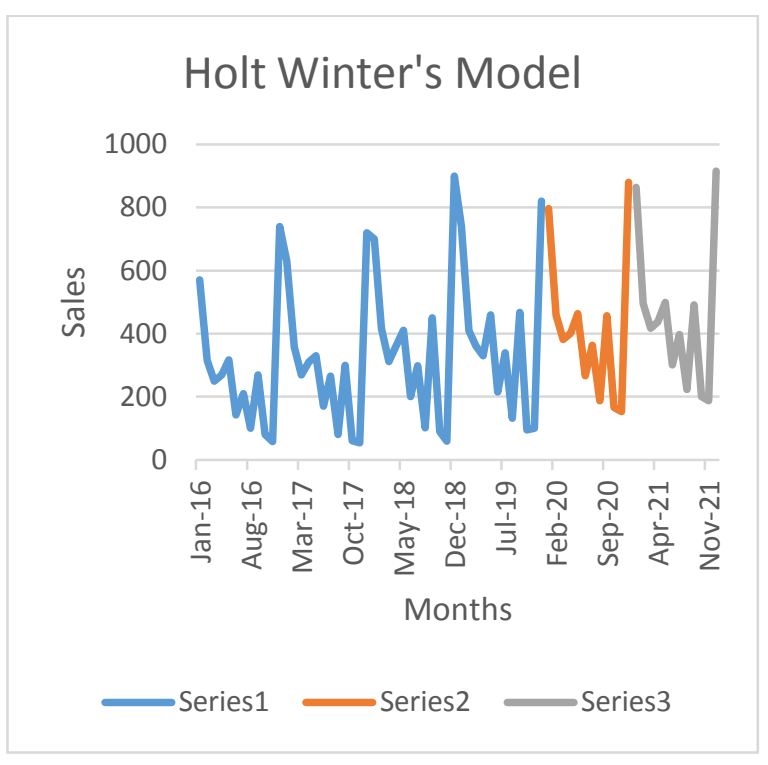

Fig 3: Output of the Holt Winter's Model for Single Phase Pump

Figure 4 shows the forecast result of the KOS pump for the year 2020 and 2021 of the ARIMA model, along with the actual sales data.

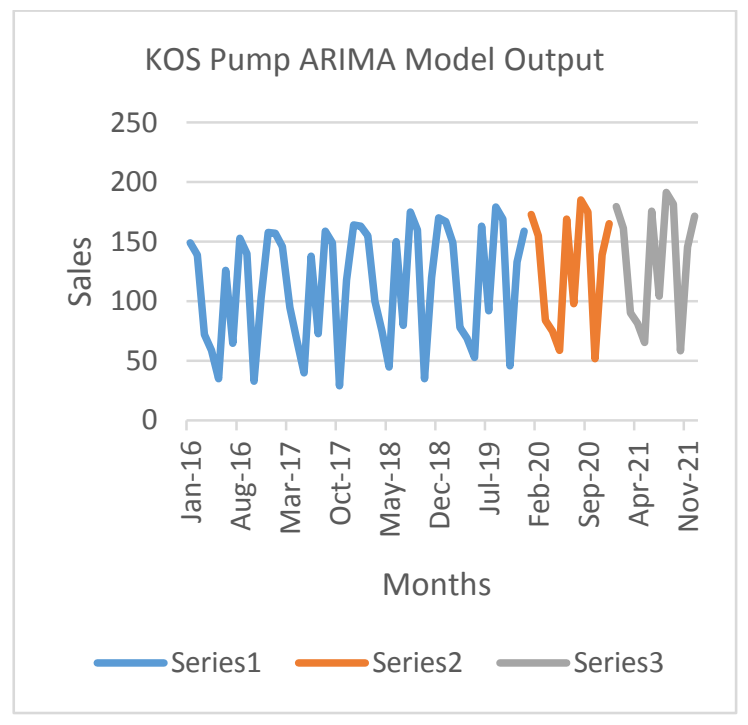

Fig 4: Output of the ARIMA Model for KOS Phase Pump 


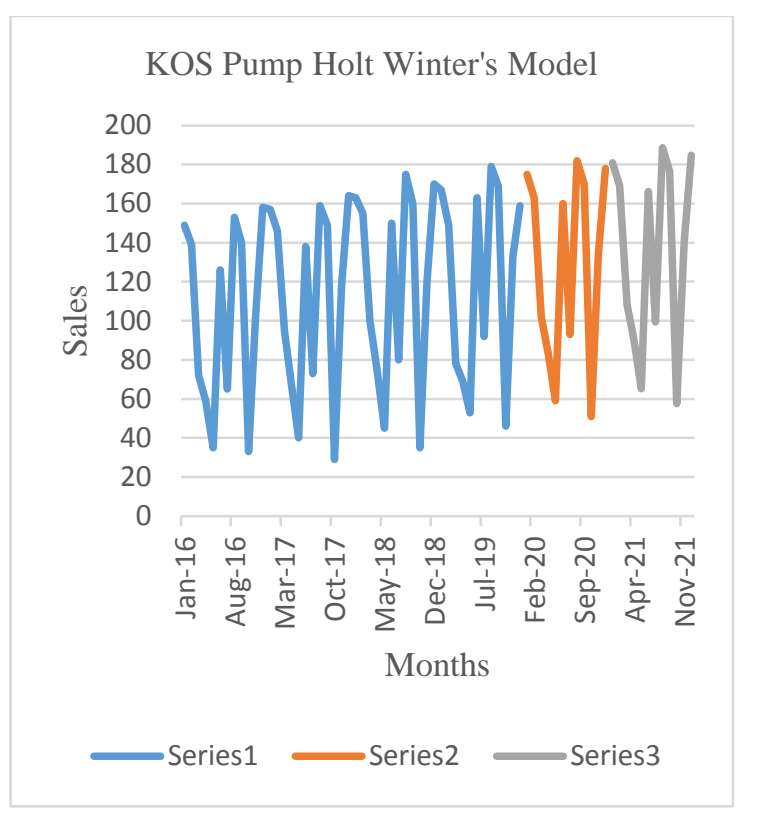

Fig 5: Output of the Holt Winter's Model for KOS Phase Pump

Figure 5 demonstrates the forecast result of KOS pump for the year 2020 and 2021 of the Holt Winter's model, along with the actual sales data.

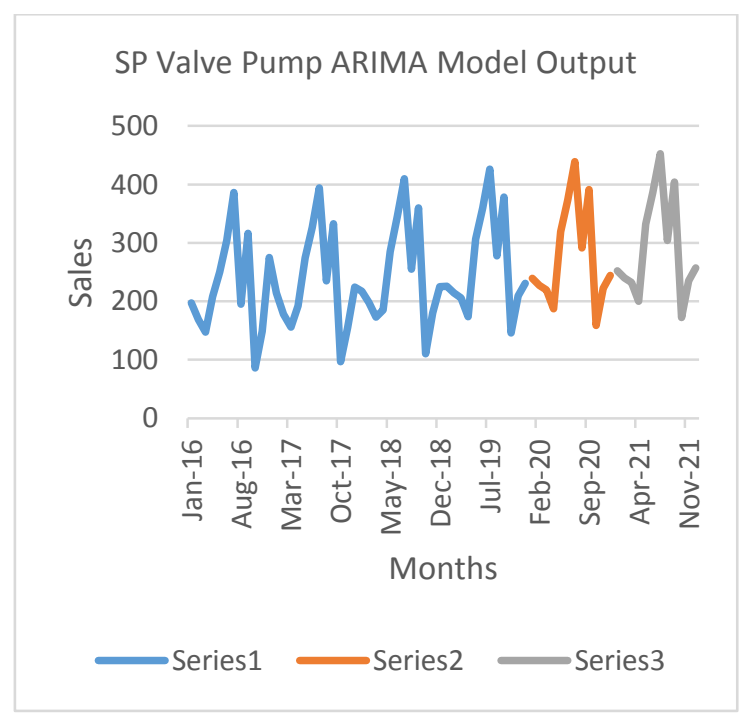

Fig 6: Output of the ARIMA Model for SP Valve Pump

Figure 6 shows the forecast result of the SP Valve pump for the year 2020 and 2021 of the ARIMA model, along with the actual sales data.

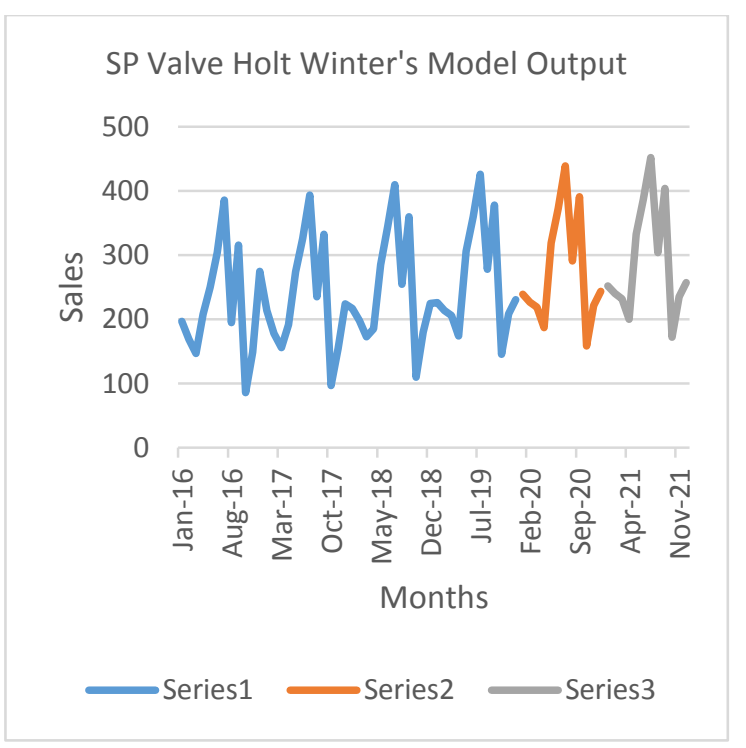

Fig 7: Output of the Holt Winter's Model for SP Valve Pump

Figure 7 demonstrates the forecast result of SP Valve Pump for the year 2020 and 2021 of Holt Winter's model, along with the actual sales data.

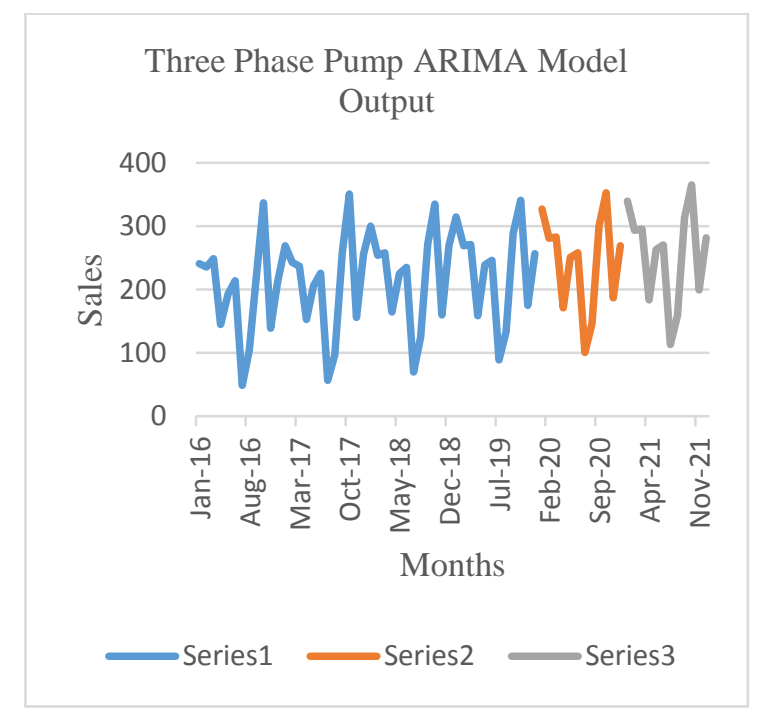

Fig 8: Output of the ARIMA Model for Three-Phase Pump

Figure 8 shows the forecast result of the Three Phase pump for the year 2020 and 2021 of the ARIMA model, along with the actual sales data. 


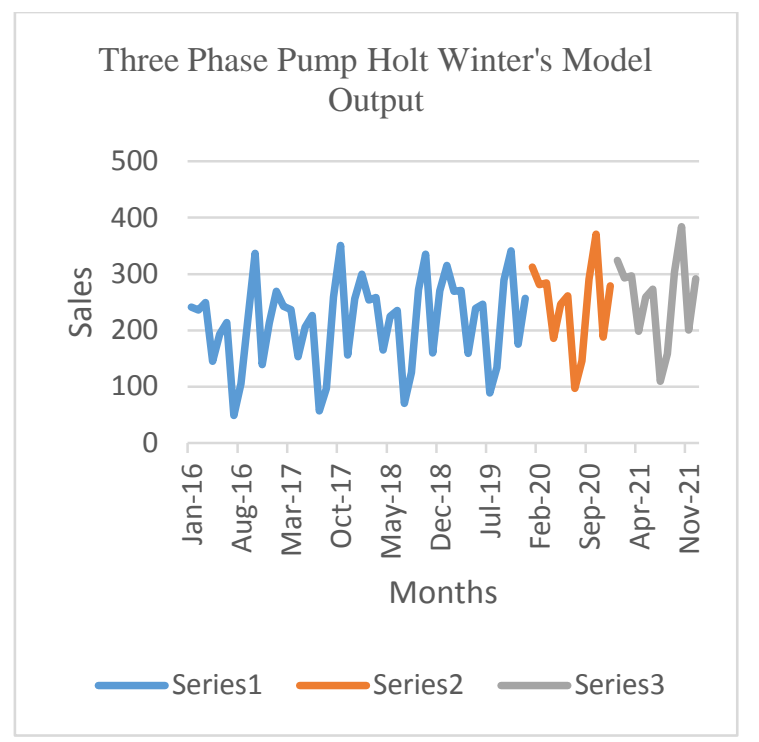

Fig 9: Output of the Holt Winter's Model for SP Valve Pump.

Figure 9 demonstrates the forecast result of Three Phase Pump for the year 2020 and 2021 of Holt Winter's model, along with the actual sales data.

Table 4: Performance Metric Results (Single Phase Pump)

\begin{tabular}{|c|c|c|}
\hline Method & MAPE & Theil's U \\
\hline HW & 9.755 & 0.1 \\
\hline ARIMA & 11.727 & 0.121 \\
\hline
\end{tabular}

Source: Research data and MS Excel

Table 5: Performance Metric Results (KOS Pump)

\begin{tabular}{|c|c|c|}
\hline Method & MAPE & Theil's U \\
\hline HW & 4.81 & 0.003 \\
\hline ARIMA & 5.79 & 0.007 \\
\hline
\end{tabular}

Source: Research data and MS Excel

Table 6: Performance Metric Results (SP Valve Pump)

\begin{tabular}{|c|c|c|}
\hline Method & MAPE & Theil's U \\
\hline HW & 5.029 & 0.0604 \\
\hline ARIMA & 5.073 & 0.0605 \\
\hline
\end{tabular}

Source: Research data and MS Excel

Table 7: Performance Metric Results (Three Phase Pump)

\begin{tabular}{|l|l|l|}
\hline Method & MAPE & Theil's U \\
\hline HW & 3.131 & 0.0081 \\
\hline ARIMA & 4.381 & 0.0299 \\
\hline \multicolumn{2}{|c|}{ Source: Research data and MS Excel }
\end{tabular}

From the data in Table 4, 5, 6 and 7 it is visible that, even by a small difference, Holt Winter's provides the prediction of sales which is more near to the actual value of the sale.
For Lewis [15], if the value of MAPE is less than or equals to $10 \%$, the forecast is termed as the good forecast. For the UThiel, the closer the value to 1 , the poorer quality is of the forecast, and if the value is close to 0 it is considered as the good forecast. When the comparison between both the models is done, even with a nominal disparity, the Holt-Winters have achieved exceptional outcome for the case under study.

\section{CONCLUSIONS}

The paper aimed to predict the expected values of the sales for the pump manufacturing company and then to compare two traditional forecasting method to determine the one best suited for future prediction for the demand of supply chain.

Both the models, that is, ARIMA and Holt-Winters are complementary but with the very minute difference in the comparison results, it is proved that HW is more suited for the prediction in this case of seasonal demand.

Although the ARIMA model gives a result which is almost near to that of Holt Winter's model, some of the limitations make it a less desirable method. Limitations like high dependence on the accuracy of the historical data and the need for constructing a new model every time a new dataset comes.

The Holt-Winters model is uncomplicated and the results received are more practical and near to the actual results, even more than the results obtained by other techniques. HoltWinters method is convenient, practical and more preferred.

\section{ACKNOWLEDGEMENT}

This paper represents not only my work at the keyboard but the endless support that I have received from many individuals and the organization. I would like to extend my sincere thanks to all of them.

I would like to extend my sincere gratitude to my supervisor Dr G.D. Thakar sir of IPE department, SGSITS, Indore. His zeal and indispensable view on the study and his commitment to providing top-notch quality of work, has left a deep imprint on me.

I convey my heartfelt gratitude to Mr Rajeev Gupta sir. His scientific inputs and motivation have always helped me, without which I couldn't have come this far. As my

Teacher and mentor, he has taught me more than I could ever give him credit for here.

\section{REFERENCES}

[1] A Kerkkanen, K. H. 2009. Demand forecasting in industrial content: Measurements and impact. Industrial Journal production Economics, 43-48.

[2] Arnaud de Myttenaere, B. G. 2017. Mean Absolute Percentage Error for Regression Models.

[3] Ayodele A. Adebiyi., A. O. 2014. Stock Price Prediction Using the ARIMA Model. International Conference on Computer Modelling and Simulation.

[4] Balpreet Singh, P. K. 2020. Sales Forecast for Amazon Sales with Time Series Modelling. 2020 First International Conference on Power, Control and Computing Technologies (ICPC2T), 38-43.

[5] BLIEMEL, F. 1973. Theil's Forecast Accuracy Coefficient: A Classification. JOURNAL OF MARKETING RESEARCH, 444-446.

[6] Box, J. R. 1994. Time Series Analysis: Forecasting and Control, 3rd Edition. Prentice Halls. 
[7] Box, P. 1965. Distribution of Residual Autocorrelations in Autoregressive-Integrated Moving Average Time Series Models. Journal of Statistical Association, 15091526.

[8] Brownlee, J. 2020, April. Machine Learning Mastery. Retrieved

from https://machinelearningmastery.com/arima-for-timeseries-forecasting-with-python/

[9] Chatfield, C. 1988. Apples, Oranges and mean squared error. International Journal of forecasting, 515-518.

[10] Chen, J. 2020, April. Investopedia. Retrieved from https://www.investopedia.com/terms/a/autoregressiveintegrated-moving-average-arima.asp

[11] G A N Pongdatu, Y. H. 2018. Seasonal Time Series Forecasting using SARIMA and Holt Winter's Exponential Smoothing. IOP Conference Series: Materials Science and Engineering.

[12] George S. Atsalakis a, *. K. 2009. Surveying stock market forecasting techniques - Part II: Soft computing methods. Elsevier, 5932-5941.

[13] JEFF TAYMAN, D. A. 1999. On the validity of MAPE as a measure of population forecast. Population Research and Policy Review, 299-322.

[14] Kumar, U. D. 2017. Business Analytics. New Delhi: Wiley India Pvt. Ltd.

[15] Lewis, C. 1997. Demand forecasting and inventory control. New York: Wiley.

[16] M. Bouzerdoum, A. M. 2013. A hybrid model (SARIMA-SVM) for short-term power forecasting of a small-scale grid-connected photovoltaic plant. Elsevier, 226-235.

[17] Makridakis, W. H. 1998. Forecasting: Methods and Applications. John Wiley and Sons.

[18] Miguel Ángel Canela, I. A. 2019. Quantitative Methods for Management. Springer.

[19] Oracle. 2020, April. Retrieved from Oracle Docs: https://docs.oracle.com/cd/E40248_01/epm.1112/cb_stati stical/frameset.htm?ch07s02s03s04.html

[20] Prothero, C. C. 1973. Box-Jenkins Seasonal Forecasting: Problems in a Case-Study. Journal of the Royal Statistical Society. Series A (General), Vol. 136, No. 3, 295-336.

[21] Rita Gamberini, F. L. 2010. Forecasting of Sporadic Demand Patterns with Seasonality and Trend Components: An Empirical Comparison between HoltWinters and (S)ARIMA Methods. Hindawi Publishing Corporation, 1-14.

[22] S. MAKRIDAKIS, A. A. 1982. The Accuracy of Extrapolation (Time Series) Methods: Results of a Forecasting Competition. Journal of Forecasting.

[23] Sungil Kim, H. K. 2016. A new metric of absolute percentage error for intermittent demand forecast. International Journal of Forecasting, 669-679.

[24] Susana Lima, A. M. 2019. Time series forecasting using Holt-Winters exponential smoothing: An application to economic data. International Conference of Computational Methods in Sciences and Engineering.

[25] Trubetskoy, G. 2020, April. Grisha. Retrieved from https://grisha.org/blog/2016/02/17/triple-exponentialsmoothing-forecasting-part-iii/

[26] Trubetskoy, G. 2020, April. Otexts. Retrieved from https://otexts.com/fpp2/seasonal-arima.html

[27] Tutorial, S. 2020, April. Retrieved from SPSS Tutorial: https://www.spss-tutorials.com/spss-what-is-it/

[28] Ummul Khair, H. F. 2017. Forecasting Error Calculation with Mean Absolute Deviation and Mean Absolute Percentage Error. Journal of Physics: Conf. Series 930.

[29] VickyChrystianSugiarto, R. D. 2016. Sales Forecasting Using Holt-Winters in Enterprise Resource Planning At Sales and Distribution Module. IEEE, 8-13.

[30] Yuchen Weng, X. W.-Y. 2019. Forecasting Horticultural Products Price Using ARIMA Model and Neural Network Based on a Large-Scale Data Set Collected by Web Crawler. IEEE, 547-553. 